\title{
Social defeat affects inflammatory signaling and exploratory behavior in mice in a sex-dependent manner
}

\author{
Randall L. Davis, Kelly McCracken, Daniel J. Buck, J. Thomas Curtis \\ Department of Pharmacology/Physiology, Oklahoma State University Center for Health Sciences, Tulsa, OK 74107, USA. \\ Correspondence to: Prof. Randall L. Davis, Department of Pharmacology/Physiology, Oklahoma State University Center for \\ Health Sciences, 1111 West 17th Street, Tulsa, OK 74107, USA. E-mail: randall.davis@okstate.edu \\ How to cite this article: Davis RL, McCracken K, Buck DJ, Curtis JT. Social defeat affects inflammatory signaling and exploratory
behavior in mice in a sex-dependent manner. Neuroimmuno/ Neuroinflammation 2021;8:146-45. \\ http://dx.doi.org/10.20517/2347-8659.2020.20
}

Received: 27 Feb 2020 First Decision: 6 May 2020 Revised: 6 Jul 2020 Accepted: 15 Jul 2020 Available online: 21 Jun 20201

Academic Editor: Athanassios P. Kyritsis Copy Editor: Cai-Hong Wang Production Editor: Tian Zhang

\begin{abstract}
Aim: Psychosocial stress negatively affects both physical and mental health; and stress-related psychiatric disorders are more common in women. Interestingly, preclinical studies have predominately investigated the effects of psychosocial stress on male mice. These studies suggest that adverse effects of psychosocial stress are due in part to the disruption of inflammatory signaling; however, the extent to which these findings translate to females remains unclear, particularly in the context of female-mediated aggression.
\end{abstract}

Methods: We investigated the effects of acute $(2 \mathrm{~h})$ and repeated social defeat (RSD; $2 \mathrm{~h} /$ day $\times 6$ days) on proinflammatory cytokine/chemokine expression in male and female C57BL/6J mice: importantly, the CD-1 aggressor mice were the same sex as the subject mice.

Results: The effects on these inflammatory factors were dependent on the duration of social defeat, sex, and tissue. A single bout of social defeat reduced brain IL-1 $\beta$ levels in females only, whereas liver IL-1 $\beta$ and CXCL10 levels increased only in males. RSD decreased brain IL-1 $\beta$ levels in males only; while liver IL-1 $\beta$ and CCL2 levels decreased only in females. RSD led to increased exploratory activity in females; behavioral changes were not apparent in males.

Conclusion: The observed effects of social defeat do not appear to be directly related to stress per se. These novel insights into sex-dependent effects of psychosocial stress on inflammatory signaling and behavior warrant further investigation.

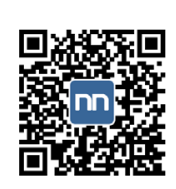


Keywords: Psychosocial stress, repeated social defeat, brain, liver, chemokines, cytokines

\section{INTRODUCTION}

Psychosocial stress encompasses a variety of stressors, including trauma, emotional/physical abuse, and bullying to name a few. These forms of stress can be acute or chronic and have far-reaching consequences on health. Indeed, irritable bowel syndrome $e^{[1]}$, metabolic syndrome $e^{[2]}$, cardiovascular disease $e^{[3]}$, and cancer $^{[4]}$ are all exacerbated by chronic psychosocial stress. Additionally, psychosocial stress is instrumental in the development and exacerbation of a range of psychiatric disorders, including anxiety disorder ${ }^{[5]}$ and post-traumatic stress disorder (PTSD) ${ }^{[6]}$. While there is still much to learn about the pathogenesis of these psychiatric disorders, increasing evidence suggests that central-peripheral crosstalk involving inflammatory signaling between the brain and peripheral tissues (e.g., gut, liver, and spleen) is critical ${ }^{[7-11]}$. The proinflammatory cytokines interleukin (IL)-1 $\beta$, IL-6, and tumor necrosis factor (TNF); and chemokine monocyte chemoattractant protein-1 (CCL2) are all inflammatory mediators implicated in psychiatric disorders $^{[12]}$. Indeed, emerging evidence suggests that inflammatory dysregulation is involved in anxiety disorders $^{[13,14]}$. For instance, a recent meta-analysis revealed that circulating levels of proinflammatory cytokines (i.e., IL-1 $\beta$, IL-6, and TNF) in patients with anxiety disorders, including PTSD, were increased compared to healthy controls ${ }^{[15]}$. Among chemokines, CCL2 has received considerable attention as a relevant biomarker and therapeutic target for the treatment of psychiatric disorders, including $\mathrm{PTSD}^{[16,17]}$. Furthermore, preclinical and clinical studies suggest that inflammatory factors are sensitive to psychosocial stress ${ }^{[18,19]}$; and anti-inflammatory agents provide therapeutic benefits in preclinical rodent models of psychiatric disease, including mood and anxiety disorders ${ }^{[20,21]}$.

Interestingly, women are more prone to stress-related psychiatric disorders than are men ${ }^{[22-24]}$; yet, the overwhelming majority of preclinical studies assessing psychosocial stress have been performed in male rodents, primarily mice. Thus, there remains much to learn about the effects of psychosocial stress on females and the importance of inflammatory signaling. New insights into sex-dependent effects of psychosocial stress on inflammatory signaling and behavior will advance the development of novel therapeutic strategies.

Repeated social defeat (RSD) is a well-established preclinical model of psychosocial stress in male mice, but the effects of RSD on female mice are less clear. While there are several variations of RSD models used for male mice, the method described by Wohleb et al. ${ }^{[25]}$ is commonly used. Briefly, a retired male breeder $\mathrm{CD}-1$ mouse (aggressor) is placed in a cage containing three C57BL/6J mice (experimental subjects) for $2 \mathrm{~h}$ daily for 6 consecutive days using a different CD-1 aggressor each day. Another frequently used model involves a 10-min exposure to the male aggressor followed by a $24 \mathrm{~h}$ period in which the aggressor and test mouse are separated by a perforated Plexiglass panel that allows for visual and olfactory stimulation without physical contact; this cycle is then repeated daily for 10-15 days ${ }^{[26,27]}$.

Although repeated psychosocial stress has often been used to test male responses, there have been relatively few studies assessing the effects of psychosocial stress on female mice, and even those studies used male aggressors $^{[28,29]}$. We, however, were interested in utilizing a female mouse as the "aggressor". Therefore, in this study, using same-sex aggressors, we investigated the effects of acute and repeated social defeat on exploratory behavior and proinflammatory cytokine/chemokine expression in male and female C57BL/6J mice.

\section{METHODS}

\section{Animals}

Seven-week-old male and female C57BL/6J mice were purchased from Jackson Laboratories (Bar Harbor, $\mathrm{ME}$ ), and housed in USDA-approved facilities for 1-2 weeks prior to experimental treatment. These mice 
were housed in same-sex trios in plastic cages $(10 \mathrm{~cm} \times 17 \mathrm{~cm} \times 28 \mathrm{~cm})$ containing corncob bedding with paper towel tubes to provide environmental enrichment. Retired breeder male and newly-mated female CD-1 mice were purchased (Jackson Laboratories) for use as aggressors and, aside from being housed singly, were maintained in the same conditions as were the $\mathrm{C} 57 \mathrm{BL} / 6 \mathrm{~J}$ mice. Mice were housed at $21{ }^{\circ} \mathrm{C}$ with a 12:12 light:dark cycle (lights on at $400 \mathrm{~h}$ and off at $1600 \mathrm{~h}$ ) and had ad libitum access to food and water. C57BL/6J and CD-1 mice were housed in separate rooms and male and females were never housed together. All experiments were approved by the Institutional Animal Care and Use Committee at Oklahoma State University - Center for Health Sciences.

\section{Social defeat}

Retired male CD-1 breeders and primiparous CD-1 females (7-14 days post-partum) were used as aggressors. Females were housed with their pups except when used as aggressors, after which they were returned to their cages. Mouse litters greater than about 7 days of age are capable of thermoregulation ${ }^{[30]}$, so they remained in their respective nests. Pups were in the same room where social aggression occurred and thus the females could hear both audible and ultrasonic vocalizations, if any.

Social defeat occurred in a testing room, separate from the housing room and followed the basic protocol described by Wohleb et al. ${ }^{[25]}$, except that they used a male aggressor (CD-1) and male experimental (C57BL/6J) mice, whereas we used males and females (same sex in each cross). Briefly, a CD-1 aggressor was placed in a clean cage $(10 \mathrm{~cm} \times 17 \mathrm{~cm} \times 28 \mathrm{~cm})$ containing three C57BL/6J mice for $2 \mathrm{~h}(1,500 \mathrm{~h}-1,700 \mathrm{~h})$ followed by immediate euthanasia of the three experimental mice to examine the acute effects of psychosocial stress, or for $2 \mathrm{~h} /$ day for 6 consecutive days to examine the effects of chronic stress. In the chronic stress model, the mice remained in the testing room for the remainder of the 6 -day period. In terms of aggressive behavior, the aggressive CD-1 mouse confronted/chased the experimental, C57BL/6J mice and repeatedly nipped at their hind quarters. After the first $5 \mathrm{~min}$, this aggression largely subsided (with intermittent confrontations), and the C57BL/6J mice retreated to the corner of the cage and huddled in a submissive manner for the remainder of the 2 -h bout. There were intermittent, brief aggressive encounters after the initial $5 \mathrm{~min}$. In the few instances that CD-1 mice did not show this aggression within the first $5 \mathrm{~min}$, they were replaced. There was no evidence of excessive aggression (e.g., biting that resulted in bleeding). Different aggressor/experimental trio pairings were used each day. After the 2-h bout, the aggressor was removed and the experimental mice left undisturbed until the next day when the procedure was repeated.

The handling and housing procedures for control mice were identical to those used for the mice exposed to social defeat, with one exception, control mice were not exposed to a CD-1 aggressor. To control for the possibility that an unfamiliar mouse in the experimental subjects' cage could induce stress, we performed an initial experiment in which a novel, same-sex C57BL/6J mouse was placed in the cage with 3 experimental C57BL/6J mice. Following the 2-h exposure period, plasma corticosterone (CORT) levels were measured as described below. We found that plasma CORT levels in mice exposed to a novel intruder were not significantly different (data not shown) from those in control mice (not exposed to an intruder). Therefore, to reduce animal usage, subsequent experiments only included control mice and mice exposed to a CD-1 aggressor.

\section{Behavioral procedures}

Twelve hours after the final bout of social defeat, exploratory locomotor activity and anxiety-like ("wallhugging") behavior were assessed using a 10-min open-field test (OFT) as previously described ${ }^{[31]}$; and a 5 -min elevated plus maze (EPM) was then used to further assess anxiety-like behavior ${ }^{[32]}$. Both tests were digitally recorded for subsequent scoring using Ethovision software. To ensure that any changes in behavior were due to RSD as opposed to the acute changes associated with the most recent bout of social defeat, we 
delayed behavioral testing until $12 \mathrm{~h}$ after the last social defeat exposure. Also, at least in male C57BL/6 mice, the literature suggests that proinflammatory factors are affected in this timeframe.

\section{Tissue collection}

For single bout of social defeat (SSD) mice, tissue/blood was collected immediately (within 30 min) after the final 2-h bout of social defeat. For RSD mice, tissue/blood was collected after behavioral testing (which occurred $12 \mathrm{~h}$ after the final bout of social defeat). In both experiments, mice were euthanized by $\mathrm{CO}_{2}$ inhalation, followed by decapitation and collection of trunk blood, brain, and liver on water-ice. Plasma was immediately separated by centrifugation and stored at $-80^{\circ} \mathrm{C}$. Both brain and liver tissues were collected and prepared using the method previously described for whole brain ${ }^{[31]}$. Briefly, tissue was homogenized in lysis buffer $(100 \mathrm{mg}$ tissue/1 $\mathrm{mL}$ ) using a sonic dismembrator. The homogenate was then centrifuged for $20 \mathrm{~min}$ at $20,000 \times g$ at $4{ }^{\circ} \mathrm{C}$. Supernatant was then stored at $-80{ }^{\circ} \mathrm{C}$.

\section{Plasma corticosterone levels}

CORT levels in the plasma were determined by ELISA according to the manufacturer's instructions (Enzo Life Sciences, Farmingdale, NY).

\section{Chemokine and cytokine expression in liver and brain}

Standard dual-antibody solid-phase immunoassays (ELISA Development Kit, Peprotech) were used for quantitation of cytokines/chemokines in tissues as previously described ${ }^{[33]}$. Values were normalized to total protein content, which was determined using the bicinchoninic acid protein assay as described previously $^{[34]}$.

\section{Statistical analysis}

PrismTM version 7.04 (GraphPad Inc., San Diego, CA) was used for statistical analysis and figure presentation. Overall analysis of dependent measures was performed using two-way analysis of variance (ANOVA) with sex and treatment (presence/absence of CD-1 aggressor) as grouping variables. Data that were 2 S.D. \pm the mean were considered outliers and removed from the analyses. When ANOVA revealed a statistically significant interaction, data were further assessed using a Fisher's LSD test. All data are presented as mean \pm S.E.M.

\section{RESULTS}

\section{Effect of social defeat on plasma corticosterone levels}

Plasma CORT levels were used as an indicator of stress. Two-way ANOVA indicated that there was a significant main effect of sex on CORT levels following 2-h SSD (males, $161.2 \pm 21.4$; females $281.7 \pm 29.8$; $\mathrm{F}_{1,31}=14.76, P<0.001$ ), but no main effect of treatment (i.e., presence/absence of CD-1 aggressor; controls, $202.1 \pm 36.2$; defeated $\left.243.1 \pm 22.9 ; \mathrm{F}_{1,31}=2.16, P=0.150\right)$. However, there was a significant interaction between sex and treatment $\left(\mathrm{F}_{1,31}=10.07, P<0.005\right)$. Pairwise comparisons showed a significant $(P<0.005)$ increase in CORT in males that were subjected to social defeat, whereas CORT levels in females were unaffected by social defeat. In males, plasma CORT was $81.3 \pm 15.0 \mathrm{ng} / \mathrm{mL}$ in controls $v s .232 .3 \pm 14.6 \mathrm{ng} / \mathrm{mL}$ following 2-h SSD. In contrast, plasma CORT in females was $309.4 \pm 41.5 \mathrm{ng} / \mathrm{mL}$ in controls $v s$. $254.0 \pm 43.1 \mathrm{ng} / \mathrm{mL}$ following 2 -h SSD.

Plasma CORT levels were similar between all groups $12 \mathrm{~h}$ following the final bout of RSD. Two-way ANOVA indicated that there were no significant main effects of sex $\left(\mathrm{F}_{1,37}=4.06 ; P=0.051\right)$ or treatment $\left(\mathrm{F}_{1,37}=2.01\right.$, $P=0.17)$ on plasma CORT levels at this point following RSD.

\section{Effect of acute social defeat on cytokine and chemokine expression}

To determine the impact of social defeat on proinflammatory cytokine/chemokine expression, we assessed IL-1 $\beta$, CCL2, and CXCL10 protein expression in brain, liver, and plasma following 2 -h SSD, and $12 \mathrm{~h}$ after 
Brain
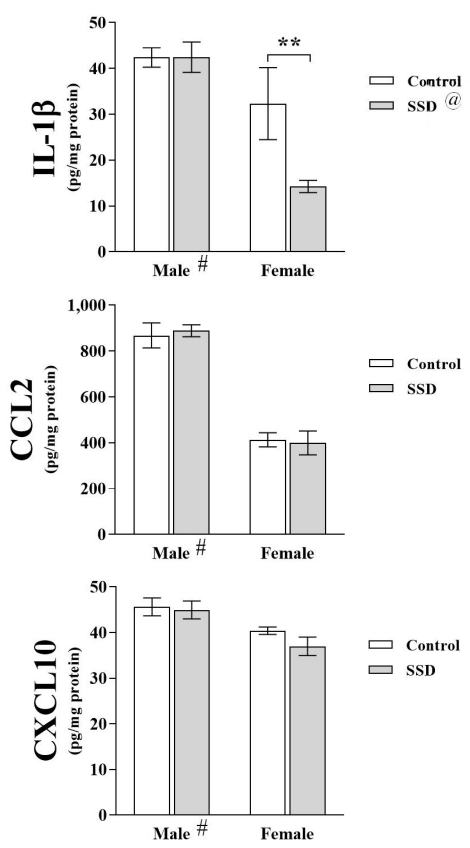

Liver
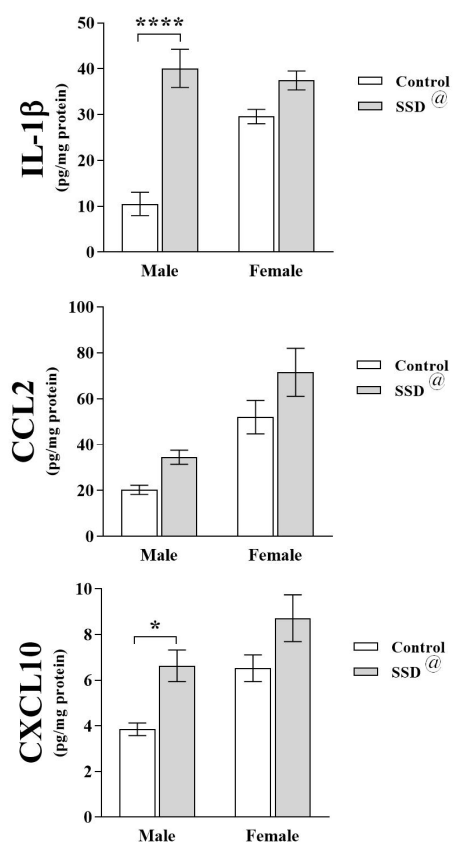

Figure 1. Effect of a single bout of social defeat (SSD) on IL-1 $13, C C L 2$, and CXCL10 protein expression in the brain and liver. C57BL/6J mice ( $n=7-9$ per group) were subjected to social defeat (exposure to a same-sex CD-1 aggressor mouse) for $2 \mathrm{~h}$; immediately thereafter, subject mice were euthanized and tissues were collected and homogenized. Cytokine/chemokine protein expression was measured by ELISA. Data were analyzed by two-way ANOVA followed by pair-wise comparisons and represent mean \pm S.E.M.; ${ }^{~}$ main effect of sex, $P<0.01 ;{ }^{\circledR}$ main effect of treatment, $P<0.05 ;{ }^{\star} P<0.05 ;{ }^{* \star} P<0.01 ;{ }^{* \star \star \star} P<0.0001$

the final bout of RSD. Due to the limited amount of plasma obtained, we were unable to measure levels of all three of these cytokines/chemokines of interest, and thus, we focused on CCL2.

Expression of the three immune factors in the brain [Figure 1] following SSD was significantly influenced by sex only (IL- $1 \beta, \mathrm{F}_{1,31}=17.67, P<0.001 ; \mathrm{CCL}_{2}, \mathrm{~F}_{1,31}=14.29, P<0.001 ; \mathrm{CXCL} 10, \mathrm{~F}_{1,31}=126.30, P<0.0001$, respectively).

There was no main effect of treatment $\left(\mathrm{F}_{1,31}=3.901, P=0.06\right)$, nor was there a sex $\mathrm{x}$ treatment interaction $\left(\mathrm{F}_{1,31}=3.961, P=0.06\right)$ for IL-1 $\beta$ expression in the brain following SSD. However, a posteriori pairwise comparison indicated that, in females, IL- $1 \beta$ levels following SSD were significantly reduced compared to those of control females $(P<0.01)$.

As shown in Figure 1, the expression of IL-1 $\beta$, CCL2, and CXCL10 in the liver following SSD was significantly influenced by both sex $\left(\mathrm{F}_{1,29}=8.23, P<0.01 ; \mathrm{F}_{1,29}=10.13, P<0.005 ; \mathrm{F}_{1,29}=23.77, P<0.001\right.$, respectively $)$ and treatment $\left(\mathrm{F}_{1,29}=42.78, P<0.001 ; \mathrm{F}_{1,29}=11.06, P<0.005 ; \mathrm{F}_{1,29}=5.73, P<0.05\right.$, respectively). IL- $1 \beta$ expression in the liver was influenced significantly by the interaction of sex and treatment $\left(\mathrm{F}_{1,29}=14.36, P<0.001\right)$. In addition, pairwise analysis revealed that following $\mathrm{SSD}$, the expression of both IL- $1 \beta$ and CXCL10 was significantly $(P<0.001 ; P<0.05$, respectively) elevated in the liver of males, compared to females.

The levels of CCL2 in the plasma were strongly affected by SSD. In males, plasma CCL2 was $3.3 \pm 1.5 \mathrm{pg} / \mathrm{mL}$ in controls vs. $60.5 \pm 7.5 \mathrm{pg} / \mathrm{mL}$ following 2-h SSD. In contrast, plasma CCL2 in females was $3.5 \pm 2.1 \mathrm{pg} / \mathrm{mL}$ in controls vs. $3.0 \pm 0.9 \mathrm{pg} / \mathrm{mL}$ following 2-h SSD. Two-way ANOVA indicated significant main effects of $\operatorname{sex}\left(\mathrm{F}_{1,30}=46.71, P<0.001\right)$, treatment $\left(\mathrm{F}_{1,30}=45.55, P<0.001\right)$, and the interaction $\left(\mathrm{F}_{1,30}=47.36, P<0.001\right)$ 
Brain
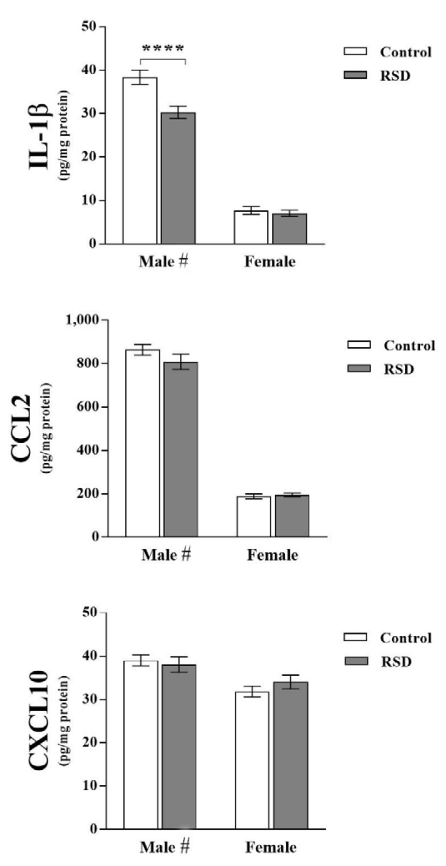

Liver
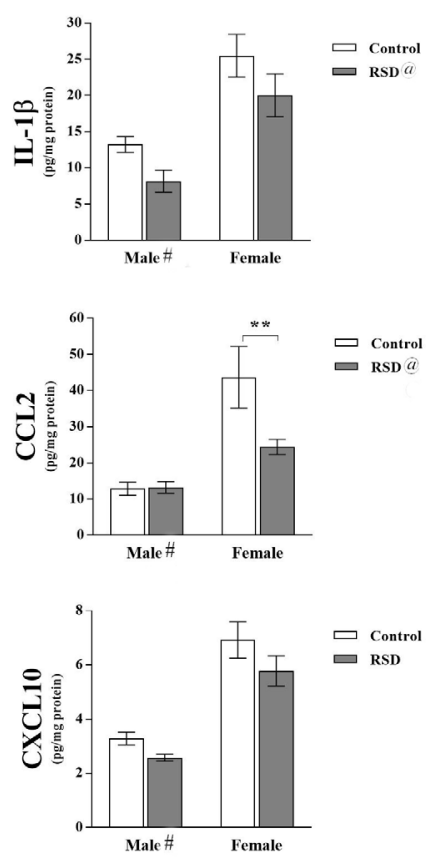

Figure 2. Effect of repeated social defeat (RSD) on IL-1 $\beta, C C L 2$, and CXCL10 protein expression in the brain and liver. C57BL/6J mice ( $n=7-12$ per group) were subjected to RSD (exposure to a same-sex CD-1 aggressor mouse for 2 h/day for 6 consecutive days); $12 \mathrm{~h}$ after the final bout of social defeat, subject mice were then euthanized and tissues were collected and homogenized. Cytokine/chemokine protein expression was measured by ELISA. Data were analyzed by two-way ANOVA followed by pair-wise comparisons and represent mean \pm S.E.M.; ${ }^{\#}$ main effect of sex, $p<0.001 ;{ }^{@}$ main effect of treatment, $P<0.05 ;{ }^{\star \star} P<0.01 ;{ }^{\star \star \star \star} P<0.0001$

of these main effects. Additionally, pairwise analysis revealed that plasma CCL2 levels were significantly $(P<0.001)$ increased in males subjected to SSD, compared to controls.

\section{Effect of RSD on cytokine and chemokine expression}

The expression of IL- $1 \beta$ in the brain following RSD was significantly affected by both sex $\left(\mathrm{F}_{1,38}=445.5\right.$, $P<0.0001)$ and treatment $\left(\mathrm{F}_{1,38}=11.65, P<0.005\right)$; and there was a significant interaction between sex and treatment $\left(\mathrm{F}_{1,38}=8.47, P<0.01\right)$ [Figure 2]. Subsequent pairwise analysis indicated that IL- $1 \beta$ was significantly $(P<0.0001)$ lower in the brain of RSD males, compared to male controls. The expression of both CXCL10 and CCL2 in the brain $12 \mathrm{~h}$ after the last bout of RSD was significantly influenced by sex $\left(\mathrm{F}_{1,37}=13.54, P<0.001\right.$ and $\mathrm{F}_{1,37}=798.0, P<0.0001$, respectively $)$, but unaffected by treatment $\left(\mathrm{F}_{1,37}=0.1595, P=0.69\right.$ and $\mathrm{F}_{1,37}=1.13, P=0.29$, respectively) [Figure 2].

Cytokine/chemokine expression in the liver also responded to RSD [Figure 2]. Expression of CXCL10 in the liver $12 \mathrm{~h}$ after the last bout of RSD was significantly influenced by $\operatorname{sex}\left(\mathrm{F}_{1,34}=49.91, P<0.001\right)$. The expression of IL- $1 \beta$ and CCL2 in the liver following RSD was significantly affected by both sex $\left(\mathrm{F}_{1,36}=27.17\right.$, $P<0.0001$ and $\mathrm{F}_{1,36}=24.69, P<0.001$, respectively $)$ and treatment $\left(\mathrm{F}_{1,36}=5.24, P<0.05\right.$ and $\mathrm{F}_{1,36}=4.99$, $P<0.05$, respectively). Also, with respect to CCL2, there was a significant interaction $\left(\mathrm{F}_{1,36}=5.40, P<0.05\right)$ between sex and treatment. Follow-up pairwise analysis indicated that following RSD, both IL-1 $\beta$ and CCL2 expression was significantly $(P<0.05$ and $P<0.01$, respectively) lower in the liver of RSD females, compared to female controls.

RSD also affected the levels of CCL2 in the plasma. Plasma CCL2 was $1.2 \pm 0.7 \mathrm{pg} / \mathrm{mL}$ in control males vs. $33.8 \pm 15.4 \mathrm{pg} / \mathrm{mL}$ in males following RSD. However, plasma CCL2 in females was $4.0 \pm 1.7 \mathrm{pg} / \mathrm{mL}$ in 
Open-Field Test
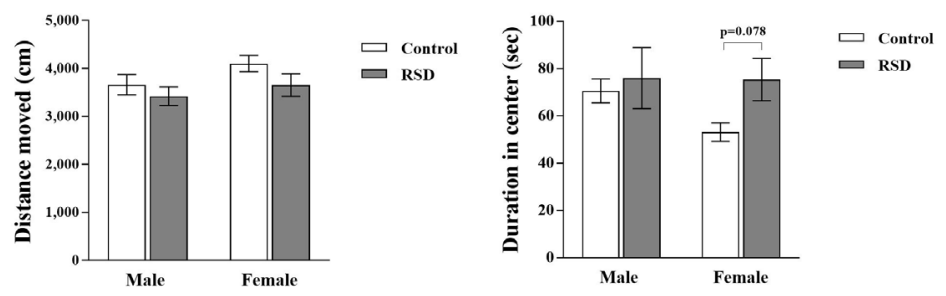

Elevated Plus Maze

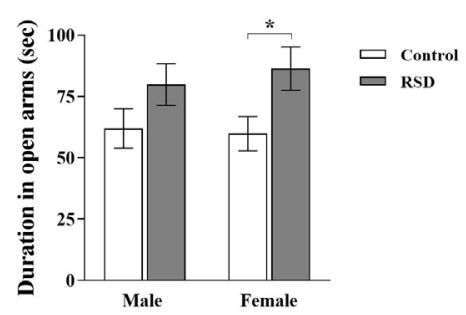

Figure 3. Effect of repeated social defeat (RSD) on locomotor activity, exploratory behavior, and anxiety-like behavior. C57BL/6J mice ( $n=8-12$ per group) were subjected to RSD (exposure to a same-sex CD-1 aggressor mouse for $2 \mathrm{~h} /$ day for 6 consecutive days). At $12 \mathrm{~h}$ after the final bout of social defeat, subjects were then subjected to behavioral testing. Behavioral tests included a 10-min open-field test, followed by a 5-min elevated plus maze. Data were analyzed by two-way ANOVA followed by pair-wise comparisons and represent mean \pm S.E.M. ${ }^{\star} P<0.05$

controls vs. $1.6 \pm 0.8 \mathrm{pg} / \mathrm{mL}$ after RSD. Two-way ANOVA indicated significant main effects of sex $\left(\mathrm{F}_{1,37}=4.58\right.$, $P<0.05)$, treatment $\left(\mathrm{F}_{1,37}=4.86, P<0.05\right)$, and an interaction $\left(\mathrm{F}_{1,37}=6.54, P<0.05\right)$ of these main effects. Subsequent pairwise analysis revealed that following RSD, plasma CCL2 levels were significantly $(P<0.005)$ increased in males exposed to RSD, compared to control males.

\section{Effect of repeated social defeat on locomotor activity, exploratory behavior, and anxiety-like behavior}

Twelve hours following the final bout of RSD, locomotor activity and exploratory behavior were assessed in an OFT [Figure 3]. There were no significant main effects of sex $\left(\mathrm{F}_{1,37}=2.50, P=0.12\right)$ or treatment $\left(\mathrm{F}_{1,37}=2.62, P=0.11\right)$ on distance moved. Exploratory behavior, as indicated by duration of time spent in the center zone during the OFT, was not significantly affected by sex $\left(\mathrm{F}_{1,37}=1.11, P=0.30\right)$ or treatment $\left(\mathrm{F}_{1,37}=2.62, P=0.11\right)$. Pairwise comparison (Fisher's LSD) suggested that females subjected to RSD tended to explore the center zone more than female controls, although not quite to the level of significance $(P=0.08)$.

The EPM was used to assess anxiety-like behavior [Figure 3]. There was a significant main effect of treatment $\left(\mathrm{F}_{1,37}=7.10, P<0.01\right)$ on time spent in the open arms of the EPM. There was neither a main effect of sex $\left(\mathrm{F}_{1,37}=0.07, P=0.79\right)$ nor an interaction between sex and treatment $\left(\mathrm{F}_{1,37}=0.27, P=0.61\right)$ on time spent in the open arms.

\section{DISCUSSION}

RSD is commonly used in preclinical studies of psychosocial stress; and results suggest that altered inflammatory signaling induced by RSD adversely contributes to liver injury, increased pain sensitivity, increased susceptibility to endotoxic shock, and behavioral deficits ${ }^{[25,35-38]}$. However, these findings stem primarily from experiments with male mice; and in the relatively few studies of RSD in female mice, the aggressor was a male ${ }^{[28,29,39]}$. While such studies have provided important information about male-mediated social defeat on females, they do not necessarily inform on the effects of a female-mediated social defeat on females. 
To our knowledge, this is the first study to use post-partum female CD-1 mice as intruders in a social defeat model. The only observable difference between male and female CD-1 aggressors was that the female aggressor had to be replaced more frequently than did male aggressor, due to insufficient aggression. Importantly though, regardless of sex, successful aggressors displayed similar levels of aggression. We were intrigued that the single bout of aggression was not sufficient to increase plasma CORT in the female C57B/6J mice. It should be noted however that our criterion for a successful CD-1 intruder-encounter included the display of submissive behavior on the part of the subjects. The fact that all encounters included such displays suggests that the subject females were experiencing social stress, despite the absence of the expected increase in circulating CORT. It is also worth noting that the baseline CORT levels were higher in females than in males, which is consistent with previous reports ${ }^{[40,41]}$. Conversely, in males, SSD induced a stress response in male $\mathrm{C} 57 \mathrm{BL} / 6 \mathrm{~J}$ mice as indicated by elevated plasma CORT, and this is similar to the findings of McQuaid et al ${ }^{[42]}$. The specific factors responsible for these sex differences in CORT responses remain to be determined.

RSD did not affect CORT levels at $12 \mathrm{~h}$ after the final bout of social defeat, which is consistent with previous reports. For instance, Niraula et al ${ }^{[43]}$ measured CORT immediately after the final bout and observed increased CORT levels. However, Zhu et al. ${ }^{[4]}$ found that CORT levels increased after acute social defeat, and found that RSD did not affect CORT levels. Furthermore, circulating CORT levels peak 30 min after social defeat, and then begin to decline toward baseline by 60 min post-defeat ${ }^{[45]}$.

In males, SSD resulted in increased expression of proinflammatory factors in the plasma (CCL2) and liver (IL- $1 \beta$ and CXCL10), whereas the factors were unaffected in the female liver. Acute social defeat did not affect cytokine/chemokine expression in the male brain; and reduced IL- $1 \beta$ levels in the female brain. The change in IL-1 $\beta$ expression in females was likely not stress-induced per se, given that CORT levels were normal in females.

Similar to SSD, RSD increased plasma CCL2 in males; however, the expression of proinflammatory factors was not affected in females. Interestingly, while the male liver was affected by SSD (increased IL-1 $\beta$ and CXCL10), the female liver was more sensitive to RSD; and the direction of change was different, with decreased levels of IL-1 $\beta$ and CXCL10 in the female liver. In the brain, IL-1 $\beta$ was the most sensitive to RSD, as indicated by reduced expression, but in males only.

These findings highlight the differential effects of both sex and duration of social stress, on inflammatory cytokine/chemokine expression. Furthermore, there are tissue-specific effects to consider. The RSDmediated increase in circulating CCL2 in males is consistent with the elevated levels of CCL2 observed in patients following psychosocial stress ${ }^{[46]}$. CCL2 is instrumental in monocyte recruitment and response to injury and infection, and thus, dysregulation of CCL2 signaling could certainly have adverse effects. For instance, we previously reported that LPS-induced sickness behavior in C57BL/6J mice is positively correlated with increased CCL2 ${ }^{[31]}$. Similarly, bacterial-induced colitis and the increased severity of the disease following social stress is CCL2-dependent ${ }^{[47]}$.

The differences in cytokine/chemokine expression in the liver following single or repeated bouts of social defeat, and between sexes are intriguing. Overall, inflammatory factors in the male liver were more sensitive to acute social stress, whereas RSD had a more profound effect on the liver in females. The biological relevance of these stress-induced effects remains to be determined, but it is critical to understand given the importance of inflammatory signaling in liver function. Indeed, mounting data indicate that psychosocial stress leads to liver pathogenesis through an inflammatory-mediated mechanism ${ }^{[48]}$. For instance, Sanchez et al ${ }^{[49]}$ reported that a single aggressive encounter was sufficient to induce liver injury, and IL-1 $\beta$ has been implicated in stress-induced liver insult ${ }^{[50]}$. There is also evidence that susceptibility to endotoxic 
shock is increased by social stress, and mechanistically, increased proinflammatory cytokine levels are involved ${ }^{[37]}$.

We found that IL- $1 \beta$ protein levels in the brain of male mice decreased following RSD. This finding is similar to a previous report in which RSD resulted in reduced IL-1 $\beta$ mRNA expression in the hippocampus ${ }^{[51]}$. Whereas Szyszkowicz et al. ${ }^{[52]}$ observed no effect of RSD on IL-1 $\beta$ mRNA expression in either the hippocampus or prefrontal cortex, others found that IL-1 $\beta$ mRNA expression in the male brain was increased after RSD ${ }^{[35]}$. However, IL-1 $\beta$ was specifically measured in macrophages that accumulated in the brain $^{[35]}$. More recently, this same group found that IL- $1 \beta$ mRNA expression also increased in the female brain (coronal slice that included hippocampus and amygdala) following $\mathrm{RSD}^{[39]}$. However, in contrast to our model, the recent study by Yin et al..$^{[39]}$ used male aggressors.

Compared to the reported effects of RSD on IL- $1 \beta$ in the brain, there has been considerably less reported about the effects of RSD on CCL2 and CXCL10 expression in the brain. Sawicki et al.$^{[19]}$ showed that six days of RSD increased CCL2 mRNA expression in the rostral cortex of male mice, but had no effect on CCL2 expression in the caudal cortex, hippocampus, or basal ganglia. More recently, McKim et al ${ }^{[35]}$ found that CCL2 mRNA expression increased in the brain following RSD; however, CCL2 was measured specifically in resident microglia. Thus, our observation that RSD does not affect CCL2 protein expression in the male brain is generally consistent with these reports. Importantly, we show that CCL2 expression in the female brain is also unaffected by RSD.

We did not detect any differences in brain CXCL1o levels in either male or female mice following RSD. In terms of comparison to other studies, there is relatively little information in the literature on the impact of RSD on CXCL10 expression in the brain; however, Tang et al ${ }^{[53]}$ recently reported that mRNA levels for this chemokine were upregulated in the brain of male mice following 10 days of RSD.

Similar to previous studies, we did not detect decreases in overall locomotor activity following RSD, suggesting that there was no induction of sickness behavior. Previous reports indicated that RSD leads to behavioral deficits, including anxiety- or depressive-like activity ${ }^{[25,35,53]}$. However, we did not observe these behavioral deficits in male mice following RSD. The basis for this difference is not clear. There was a marginal effect of treatment in the amount of time spent in the open arms by the males, but any effect was smaller than was the corresponding effect in females. It is possible that larger sample sizes may have revealed more substantial changes. In females, RSD actually increased exploratory activity. This finding is particularly interesting in the context of increased risk-taking behavior that is often observed in patients that have experienced psychosocial stress, including bullying ${ }^{[54-56]}$. Further investigation is of course required to definitively make this connection.

There are several possible explanations for the differences in the RSD-induced effects on proinflammatory cytokine/chemokine expression and behavior observed in our study, compared to the findings in previous reports. First, there are clear differences in the models of RSD, e.g., type of aggressor, duration and number of social defeat bouts, and presence/absence of continued visual and olfactory stimulation following the bout varied. Second, we assessed cytokine/chemokine expression at the protein level in whole brain homogenates, whereas others assessed mRNA in select brain regions and specific cell types. Lastly, the time point of tissue collection/behavioral assessment following RSD varied to some extent between these studies. For instance, we measured behavior and expression of inflammatory factors $12 \mathrm{~h}$ after the final bout of social defeat, whereas others typically measured at $14-24 \mathrm{~h}$ after the last bout of social defeat ${ }^{[19,25,45]}$.

In our follow-up investigations, it will be important to assess inflammatory factors and behavior at additional time points both prior to and after the $12 \mathrm{~h}$ time point assessed in this study. One limitation of 
our study was that we measured the expression of inflammatory factors in whole brain homogenates, which may explain the lack of treatment effect on cytokine/chemokine expression. Therefore, it will be important in future investigations to assess the expression of these inflammatory mediators in specific brain regions, such as the hippocampus and prefrontal cortex. Similarly, we expect to measure mRNA expression of cytokines/chemokines in microglia and astrocytes following RSD. Lastly, it will be important to include additional behavioral tests, and assess additional behaviors, such as depressive-like behavior.

In conclusion, to our knowledge, this is the first report on the effects of female-female social defeat on proinflammatory cytokine/chemokine expression in liver and brain, and on exploratory behavior. This report provides interesting and novel findings about the differential effects of acute and chronic social defeat on proinflammatory cytokines/chemokines and about the extent to which these effects are tissueand sex-dependent. There is considerable evidence that liver-brain crosstalk contributes to mood disorders, and thus, the effects of RSD on inflammatory factors in the liver and brain may ultimately yield critical insights into the detrimental effects of psychosocial stress, particularly on anxiety and mood disorders.

\section{DECLARATIONS}

\section{Authors' contributions}

Concept, experimental design, literature review, statistical analysis, manuscript preparation: Davis RL

Performed experiments, data acquisition and analysis, and manuscript editing: McCracken K, Buck DJ

Experimental design, statistical analysis, manuscript editing: Curtis JT

\section{Availability of data and materials}

Not applicable.

\section{Financial support and sponsorship}

This work was supported in part by Oklahoma Health Research Program (HR 18-033) and by Oklahoma State University Center for Health Sciences, Intramural funds (RLD).

\section{Conflicts of interest}

All authors declared that there are no conflicts of interest.

\section{Ethical approval and consent to participate}

Not applicable.

\section{Consent for publication}

Not applicable.

\section{Copyright}

(c) The Author(s) 2021.

\section{REFERENCES}

1. Creed F. Review article: the incidence and risk factors for irritable bowel syndrome in population-based studies. Aliment Pharmacol Ther 2019;50:507-16

2. Kuo WC, Bratzke LC, Oakley LD, Kuo F, Wang H, et al. The association between psychological stress and metabolic syndrome: A systematic review and meta-analysis. Obes Rev 2019;20:1651-64.

3. Dar T, Radfar A, Abohashem S, Pitman RK, Tawakol A, et al. Psychosocial stress and cardiovascular disease. Curr Treat Options Cardiovasc Med 2019;21:23.

4. Antoni MH, Dhabhar FS. The impact of psychosocial stress and stress management on immune responses in patients with cancer. Cancer 2019;125:1417-31.

5. Moreno-Peral P, Conejo-Ceron S, Motrico E, Rodriguez-Morejon A, Fernandez A, et al. Risk factors for the onset of panic and generalised anxiety disorders in the general adult population: a systematic review of cohort studies. J Affect Disord 2014;168:337-48. 
6. Malinauskiene V, Einarsen S. Workplace bullying and post-traumatic stress symptoms among family physicians in Lithuania: an occupation and region specific approach. Int J Occup Med Environ Health 2014;27:919-32.

7. Ambree O, Ruland C, Scheu S, Arolt V, Alferink J. Alterations of the innate immune system in susceptibility and resilience after social defeat stress. Front Behav Neurosci 2018;12:141.

8. Hodes GE, Kana V, Menard C, Merad M, Russo SJ. Neuroimmune mechanisms of depression. Nat Neurosci 2015;18:1386-93.

9. D'Mello C, Swain MG. Liver-brain interactions in inflammatory liver diseases: implications for fatigue and mood disorders. Brain Behav Immun 2014;35:9-20.

10. Grochowska M, Wojnar M, Radkowski M. The gut microbiota in neuropsychiatric disorders. Acta Neurobiol Exp (Wars) 2018;78:69-81.

11. Reader BF, Jarrett BL, McKim DB, Wohleb ES, Godbout JP, et al. Peripheral and central effects of repeated social defeat stress: monocyte trafficking, microglial activation, and anxiety. Neuroscience 2015;289:429-42.

12. Kohler CA, Freitas TH, Stubbs B, Maes M, Solmi M, et al. Peripheral alterations in cytokine and chemokine levels after antidepressant drug treatment for major depressive disorder: systematic review and meta-analysis. Mol Neurobiol 2018;55:4195-206.

13. Vogelzangs N, Beekman AT, de Jonge P, Penninx BW. Anxiety disorders and inflammation in a large adult cohort. Transl Psychiatry 2013;3:e249.

14. Felger JC. Imaging the role of inflammation in mood and anxiety-related disorders. Curr Neuropharmacol 2018;16:533-58.

15. Renna ME, Quintero JM, Soffer A, Pino M, Ader L, et al. A pilot study of emotion regulation therapy for generalized anxiety and depression: findings from a diverse sample of young adults. Behav Ther 2018;49:403-18.

16. Stuart MJ, Baune BT. Chemokines and chemokine receptors in mood disorders, schizophrenia, and cognitive impairment: a systematic review of biomarker studies. Neurosci Biobehav Rev 2014;42:93-115.

17. Dalgard C, Eidelman O, Jozwik C, Olsen CH, Srivastava M, et al. The MCP-4/MCP-1 ratio in plasma is a candidate circadian biomarker for chronic post-traumatic stress disorder. Transl Psychiatry 2017;7:e1025.

18. Fleshner M, Frank M, Maier SF. Danger signals and inflammasomes: stress-evoked sterile inflammation in mood disorders. Neuropsychopharmacology 2017;42:36-45.

19. Sawicki CM, McKim DB, Wohleb ES, Jarrett BL, Reader BF, et al. Social defeat promotes a reactive endothelium in a brain regiondependent manner with increased expression of key adhesion molecules, selectins and chemokines associated with the recruitment of myeloid cells to the brain. Neuroscience 2015;302:151-64.

20. Ramirez K, Shea DT, McKim DB, Reader BF, Sheridan JF. Imipramine attenuates neuroinflammatory signaling and reverses stressinduced social avoidance. Brain Behav Immun 2015;46:212-20.

21. Kohler O, Krogh J, Mors O, Benros ME. Inflammation in depression and the potential for anti-inflammatory treatment. Curr Neuropharmacol 2016;14:732-42.

22. Gustavson K, Knudsen AK, Nesvag R, Knudsen GP, Vollset SE, et al. Prevalence and stability of mental disorders among young adults: findings from a longitudinal study. BMC Psychiatry 2018;18:65.

23. Duckers MLA, Olff M. Does the vulnerability paradox in PTSD apply to women and men? An exploratory study. J Trauma Stress 2017;30:200-4.

24. Navarro-Mateu F, Tormo MJ, Salmeron D, Vilagut G, Navarro C, et al. Prevalence of mental disorders in the south-east of spain, one of the european regions most affected by the economic crisis: the cross-sectional PEGASUS-murcia project. PLoS One 2015;10:e0137293.

25. Wohleb ES, Hanke ML, Corona AW, Powell ND, Stiner LM, et al. beta-adrenergic receptor antagonism prevents anxiety-like behavior and microglial reactivity induced by repeated social defeat. J Neurosci 2011;31:6277-88.

26. Iniguez SD, Aubry A, Riggs LM, Alipio JB, Zanca RM, et al. Social defeat stress induces depression-like behavior and alters spine morphology in the hippocampus of adolescent male C57BL/6 mice. Neurobiol Stress 2016;5:54-64.

27. Fuertig R, Azzinnari D, Bergamini G, Cathomas F, Sigrist H, et al. Mouse chronic social stress increases blood and brain kynurenine pathway activity and fear behaviour: both effects are reversed by inhibition of indoleamine 2,3-dioxygenase. Brain Behav Immun 2016;54:59-72.

28. Takahashi A, Chung JR, Zhang S, Zhang H, Grossman Y, et al. Establishment of a repeated social defeat stress model in female mice. Sci Rep 2017;7:12838.

29. Harris AZ, Atsak P, Bretton ZH, Holt ES, Alam R, et al. A novel method for chronic social defeat stress in female mice. Neuropsychopharmacology 2018;43:1276-83.

30. Harshaw C, Alberts JR. Group and individual regulation of physiology and behavior: a behavioral, thermographic, and acoustic study of mouse development. Phys Behav 2012;106:670-82.

31. Davis RL, Stevens CW, Thomas Curtis J. The opioid antagonist, beta-funaltrexamine, inhibits lipopolysaccharide-induced neuroinflammation and reduces sickness behavior in mice. Phys Behav 2017;173:52-60.

32. Walf AA, Frye CA. The use of the elevated plus maze as an assay of anxiety-related behavior in rodents. Nat Protoc 2007;2:322-8.

33. Davis RL, Buck DJ, Saffarian N, Stevens CW. The opioid antagonist, beta-funaltrexamine, inhibits chemokine expression in human astroglial cells. J Neuroimmunol 2007;186:141-9.

34. Davis RL, Dertien J, Syapin PJ. Ethanol-induced modulation of inducible nitric-oxide synthase activity in human A172 astrocytoma cells. Alcohol Clin Exp Res 2002;26:1404-11.

35. McKim DB, Weber MD, Niraula A, Sawicki CM, Liu X, et al. Microglial recruitment of IL-1beta-producing monocytes to brain endothelium causes stress-induced anxiety. Mol Psych 2018;23:1421-31.

36. Gautam A, D'Arpa P, Donohue DE, Muhie S, Chakraborty N, et al. Acute and chronic plasma metabolomic and liver transcriptomic stress effects in a mouse model with features of post-traumatic stress disorder. PLoS One 2015;10:e117092. 
37. Quan N, Avitsur R, Stark JL, He L, Shah M, et al. Social stress increases the susceptibility to endotoxic shock. J Neuroimmunol 2011;115:36-45.

38. Sawicki CM, Kim JK, Weber MD, Faw TD, McKim DB, et al. Microglia promote increased pain behavior through enhanced inflammation in the spinal cord during repeated social defeat stress. J Neurosci 2019;39:1139-49.

39. Yin W, Gallagher NR, Sawicki CM, McKim DB, Godbout JP, et al. Repeated social defeat in female mice induces anxiety-like behavior associated with enhanced myelopoiesis and increased monocyte accumulation in the brain. Brain Behav Immun 2019;78:131-42.

40. Malisch JL, Saltzman W, Gomes FR, Rezende EL, Jeske DR, et al. Baseline and stress-induced plasma corticosterone concentrations of mice selectively bread for high voluntary wheel running. Physiol Biochem Zool 2007;80:146-56.

41. Garcia GK, Mattingly AJ, Robinson GP, Laitano O, King MA, et al. Sex-dependent responses to exertional heat stroke in mice. J Appl Physiol 2018;125:841-9.

42. McQuaid RJ, Audet MC, Jacobson-Pick S, Anisman H. Environmental enrichment influences brain cytokine variations elicited by social defeat in mice. Psychoneuroendocrinology 2013;38:987-96.

43. Niraula A, Wang Y, Godbout JP, Sheridan JF. Corticosterone production during repeated socail defeat causes monocyte mobilization from bone marrow, glucocorticoid resistance, and neurovascular adhesion molecule expression. J Neurosci 2018;38:2328-40.

44. Zhu Y, Klomparens EA, Guo S, Geng X. Neuroinflammation caused by mental stress: the effect of chronic restraint stress and acute repeated social defeat stress in mice. Neurol Res 2019;41:762-9.

45. Keeney A, Jessop DS, Harbuz MS, Marsden CA, Hogg S, et al. Differential effects of acute and chronic social defeat stress on hypothalamic-pituitary-adrenal axis function and hippocampal serotonin release in mice. J Neuroendocrinol 2006;18:330-8.

46. Asberg M, Nygren A, Leopardi R, Rylander G, Peterson U, et al. Novel biochemical markers of psychosocial stress in women. PLoS One 2009;4:e3590.

47. Mackos AR, Galley JD, Eubank TD, Easterling RS, Parry NM, et al. Social stress-enhanced severity of Citrobacter rodentium-induced colitis is CCL2-dependent and attenuated by probiotic Lactobacillus reuteri. Mucosal Immunol 2016;9:515-26.

48. Vere CC, Streba CT, Streba LM, Ionescu AG, Sima F. Psychosocial stress and liver disease status. World J Gastroenterol 2009;15:2980-6.

49. Sanchez O, Viladrich M, Ramirez I, Soley M. Liver injury after an aggressive encounter in male mice. Am J Physiol Regul Integr Comp Physiol 2007;293:R1908-16.

50. Tseilikman V, Kozochkin D, Synitsky A, Sibiriak S, Tseilikman O, et al. Does stress-induced release of interleukin-1 cause liver injury? Cell Mol Neurobiol 2012;32:1069-78.

51. Bartolomucci A, Palanza P, Parmigiani S, Pederzani T, Merlot E, et al. Chronic psychosocial stress down-regulates central cytokines mRNA. Brain Res Bull 2003;62:173-8.

52. Szyszkowicz JK, Wong A, Anisman H, Merali Z, Audet MC. Implications of the gut microbiota in vulnerability to the social avoidance effects of chronic social defeat in male mice. Brain Behav Immun 2017;66:45-55.

53. Tang J, Yu W, Chen S, Gao Z, Xiao B. Microglia polarization and endoplasmic reticulum stress in chronic social defeat stress induced depression mouse. Neurochem Res 2018;43:985-94.

54. Liang H, Flisher AJ, Lombard CJ. Bullying, violence, and risk behavior in South African school students. Child Abuse Negl 2007;31:16171.

55. Poon K. Understanding risk-taking behavior in bullies, victims, and bully victims using cognitive- and emotion-focused approaches. Front Psychol 2016;7:1838.

56. Nowacki J, Heekeren HR, Deuter CE, Joerissen JD, Schroder A, et al. Decision making in response to physiological and combined physiological and psychosocial stress. Behav Neurosci 2019;133:59-67. 